The INL is a

U.S. Department of Energy

National Laboratory

operated by

Battelle Energy Alliance

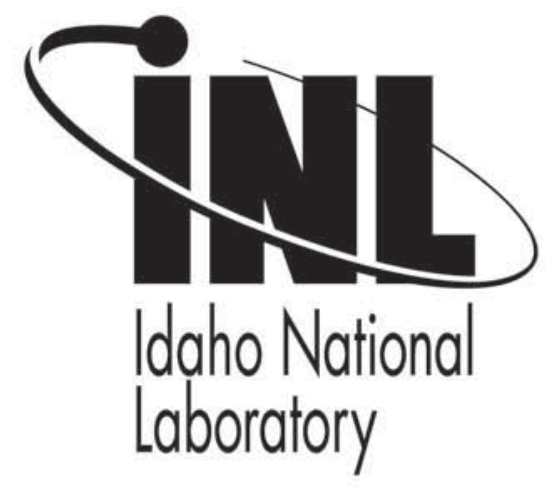

\title{
Characterization of Elevated Temperature Properties of Heat Exchanger and Steam Generator Alloys
}

\section{HTR 2010}

J. K. Wright

L. J. Carroll

C. J. Cabet

T. Lillo

J. K. Benz

J. A. Simpson

W. R. Lloyd

J. A. Chapman

R. N. Wright

\section{October 2010}

This is a preprint of a paper intended for publication in a journal or proceedings. Since changes may be made before publication, this preprint should not be cited or reproduced without permission of the author. This document was prepared as an account of work sponsored by an agency of the United States Government. Neither the United States Government nor any agency thereof, or any of their employees, makes any warranty, expressed or implied, or assumes any legal liability or responsibility for any third party's use, or the results of such use, of any information, apparatus, product or process disclosed in this report, or represents that its use by such third party would not infringe privately owned rights. The views expressed in this paper are not necessarily those of the United States Government or the sponsoring agency. 


\title{
Characterization of Elevated Temperature Properties of Heat Exchanger and Steam Generator Alloys
}

\author{
J. K. Wright, L. J. Carroll, C. J. Cabet, T. Lillo, J. K. Benz, J. A. Simpson, W. R. Lloyd, J. A. Chapman, and \\ R. N. Wright \\ Next Generation Nuclear Plant High Temperature Metals Project \\ Idaho National Laboratory \\ P. O. Box 1625 \\ Idaho Falls, ID \\ USA \\ phone:+12-208-526-9723, Jill.Wright@inl.gov
}

\begin{abstract}
The Next Generation Nuclear Plant project is considering Alloy $800 \mathrm{H}$ and Alloy 617 for steam generator and intermediate heat exchangers. It is envisioned that a steam generator would operate with reactor outlet temperatures from 750 to $800^{\circ} \mathrm{C}$, while an intermediate heat exchanger for primary to secondary helium would operate up to an outlet temperature of $950^{\circ} \mathrm{C}$. Although both alloys are of interest due in part to their technical maturity, a number of specific properties require further characterization for design of nuclear components. Strain rate sensitivity of both alloys has been characterized and is found to be significant above $600^{\circ} \mathrm{C}$. Both alloys also exhibit dynamic strain aging, characterized by serrated flow, over a wide range of temperatures and strain rates. High temperature tensile testing of Alloy 617 and Alloy $800 \mathrm{H}$ has been conducted over a range of temperatures. Dynamic strain aging is a concern for these materials since it is observed to result in reduced ductility for many solid solution alloys. Creep, fatigue, and creep-fatigue properties of Alloy 617 have been measured as well, with the goal of determining the influence of the temperature, strain rate and atmosphere on the creep fatigue life of Alloy 617. Elevated temperature properties and implications for codification of the alloys will be described.
\end{abstract}

\section{INTRODUCTION}

The Next Generation Nuclear Plant (NGNP) being developed in the United States is a Very High Temperature Nuclear Reactor (VHTR) with helium as the primary coolant. The plant size, reactor thermal power, and core configuration will ensure passive decay heat removal without fuel damage or radioactive material releases during accidents. The basic feasibility of the concept has been established in former High Temperature Gas Reactors (HTGRs) and demonstration plants currently operating. Therefore, NGNP is focused on building a first-of-its-kind commercial-scale plant, to demonstrate the use of nuclear power for electricity, process heat and hydrogen production rather than simply confirming feasibility of the HTGR concept. The NGNP is intended to have a license period of 60 years and the most likely design features an outlet gas temperature of $750^{\circ} \mathrm{C}$, a steam generator, and possibly an intermediate heat exchanger (IHX) with helium as both the primary and secondary coolant. The helium is expected to contain low levels of residual impurities that can react with the high temperature materials causing corrosion. Subsequent VHTRs may incorporate variations of this baseline design to allow eventual operation at gas outlet temperatures up to $950^{\circ} \mathrm{C}$. The combination of high temperature operation and long duration of service requires structural materials with good thermal stability as well as high temperature creep and oxidation resistance. Based on these material requirements Alloy 617 (UNS N06617) and Alloy $800 \mathrm{H}$ (UNS N08810) are the leading candidate alloys for the high temperature components. 


\section{MATERIALS}

Alloy 617 is approved for non-nuclear construction in ASME Code Section I and Section VIII, Division 1 but is not currently qualified for nuclear use in ASME Code Section III. A draft Code Case was developed in the 1980's to qualify the alloy for nuclear service but efforts were stopped before the approval process was completed.

Alloy 617 is strengthened by solid solution hardening provided by the alloy elements chromium, cobalt and molybdenum as well as by intra- and inter-granular carbide precipitates. The high temperature oxidation resistance is derived from the high nickel and chromium content.

Alloy $800 \mathrm{H}$ is the only alloy among the proposed materials for this application that is ASME Code qualified for use in nuclear systems, but only for temperatures up to $\sim 760^{\circ} \mathrm{C}$ and a maximum service time of 300,000 hours. Alloy $800 \mathrm{H}$ has lower creep rupture strength and less resistance to oxidation than Alloy 617.

Alloy $800 \mathrm{H}$ is an iron-based alloy, although like Alloy 617, it has a solid-solution strengthened austenitic structure. It is free of precipitates in the solution annealed condition; however, upon aging, $\gamma$ ' precipitates can form and reduce the tensile and creep ductility. The volume fraction of precipitates is controlled by limiting the concentration of $\mathrm{Al}$ and $\mathrm{Ti}$. In addition, an annealing treatment, specified to produce an ASTM grain size of 5 or coarser, and a controlled carbon content result in improved creep rupture properties.

The composition of the alloys is given in Table 1. The microstructure of the Alloy 617 plate used in the work reported in this paper is shown in Fig. 1.
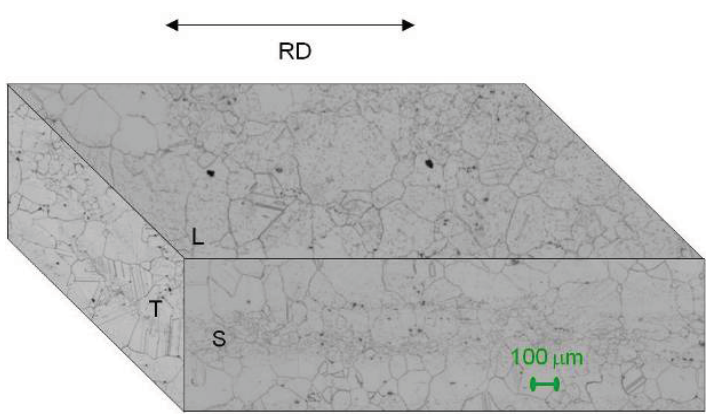

Fig. 1: Microstructure of the as-annealed Alloy 617.

\section{PROPERTY CHARACTERIZATION}

Both Alloy 617 and Alloy $800 \mathrm{H}$ have been extensively studied, however some additional property characterization is required. A review of the database developed for the draft Code Case for Alloy 617 identified the need for complementary creep-fatigue data as well as an understanding of the environmental effects of impure helium. Alloy $800 \mathrm{H}$ was the primary high temperature alloy used in both the German HTGR programs and the Fort St. Vrain steam generator. However a current effort to extend the ASME allowable stresses of Alloy $800 \mathrm{H}$, perhaps to as high as $900^{\circ} \mathrm{C}$ and 60 years, will require some supplementary data.

In addition to property characterization needed for ASME codification, data is needed to support constitutive modeling and Nuclear Regulatory Commission (NRC) licensing.

\section{III.A. Tensile Properties}

ASME Subsection NH requires a timeindependent allowable stress, $S_{m}$ as one of the fundamental design inputs. Characterization of the tensile properties will provide input to $\mathrm{S}_{\mathrm{m}}$ and is therefore required to develop a Code Case for Alloy 617. High temperature tensile properties are necessary to extend the ASME allowable temperatures of Alloy $800 \mathrm{H}$.

\section{III.B. Strain Rate Sensitivity}

The tensile curves of Alloy 617 are highly dependent on strain rates, with flow stress increasing with strain rate at high temperatures. Thus, strain rate will affect the allowable stress values in the temperature range of interest to NGNP hot gas piping and IHX components. Strain rates of $10^{-7} / \mathrm{sec}$ and $10^{-8} / \mathrm{sec}$ are expected in an IHX application of a high temperature reactor (HTR).[1] However, typical tensile tests are performed at more rapid strain rates (approximately $10^{-4} / \mathrm{sec}$ in this study). A constitutive model of the high temperature material behavior needs to take the strain rate into account. It is difficult to separate the effects of temperature, strain range, strain rate and environment as they have complex interrelationships. A number of tests have been designed to probe the rate (timedependent) response of the alloys. They include tests at different strain rates, strain rate jump, cyclic, short-term creep and stress relaxation testing, all at uniform temperatures. The full spectrum of strain rate effects on flow stress will be investigated.

\begin{tabular}{|c|c|c|c|c|c|c|c|c|c|c|c|}
\hline Alloy & $\mathrm{Ni}$ & $\mathrm{C}$ & $\mathrm{Cr}$ & $\mathrm{Co}$ & $\mathrm{Mo}$ & $\mathrm{Fe}$ & $\mathrm{Al}$ & $\mathrm{Ti}$ & $\mathrm{Si}$ & $\mathrm{Cu}$ & $\mathrm{Mn}$ \\
\hline 617 & $\mathrm{bal}$ & 0.05 & 22.2 & 11.6 & 8.6 & 1.6 & 1.1 & 0.4 & 0.1 & 0.04 & 0.1 \\
\hline $800 \mathrm{H}$ & 30.45 & 0.06 & 19.30 & 0.11 & 0.21 & $\mathrm{bal}$ & 0.43 & 0.45 & 0.37 & 0.21 & 1.31 \\
\hline
\end{tabular}

Table 1: Alloy 617 (heat 31426 ) and alloy $800 \mathrm{H}$ (heat 37458 ) composition in wt $\%$. 
Although generally not very sensitive to strain rate at lower temperatures, the yield and tensile strengths of $800 \mathrm{H}$ depend on the strain rate at $760^{\circ} \mathrm{C}$ and above, with lower strengths expected for lower strain rates.[2] To better understand the range of applicability of the ASME recommended values, testing at various strain rates is needed.

\section{III.C. Creep Fatigue}

Creep-fatigue deformation is a combination of creep damage and fatigue damage and is expected to be the primary damage mode for the NGNP IHX. Transients during start up and shut down produce cyclic loadings, while the stresses relax during steady power operation inducing creep damage. A preliminary evaluation of the NGNP operating transients indicates the normal cyclic service will consist of several hundred very slow transients with hold times on the order of 1,000 hours. There is also the possibility of a limited number (less than 10) of off-normal cycles with more rapid ramp rates and shorter hold times. This raises the critical issue of whether the creep-fatigue behavior of Alloy 617 saturates with increasing hold time (i.e, does the number of cycles to failure stop decreasing, as the hold time increases).

Creep-fatigue testing (strain-controlled fatigue with a hold time at the peak tensile strain) is performed in a laboratory setting to reproduce the expected damage mode. A comprehensive program is underway to assess the creep-fatigue resistance of Alloy 617. The long term goal is to determine the influence of the temperature, strain rate, and atmosphere on the creep-fatigue life of Alloy 617 . Creep-fatigue results will be combined with creep results to develop a creep-fatigue interaction diagram for Alloy 617.

\section{III.D. Creep}

ASME Section III Subsection NH criteria for estimating the time-dependent allowable stress, $\mathrm{S}_{\mathrm{t}}$ are based on materials that exhibit a classical creep response. Fig. 2 illustrates typical creep behavior; most of the creep behavior is linear, occurring in the secondary creep regime. Alloy 617 exhibits classical primary, secondary, and tertiary regimes in the creep response at temperatures below $800^{\circ} \mathrm{C}$; but secondary creep is hardly noticeable in the creep curves at $800^{\circ} \mathrm{C}$ and above, as shown in Fig. 3. After the initial primary creep regime, the creep rate increases gradually until rupture. Thus the onset of tertiary creep based on the classical definition occurs at very short time. Information is needed on whether the gradually increasing creep curve is a manifestation of different deformation mechanisms typified by dislocation generation and motion, or if it corresponds to creep damage such as grain boundary cavitation and cracking reminiscent of those occurring in the classical tertiary creep regime. Interrupted creep and stress rupture tests are planned with expected durations of up to 7 years.

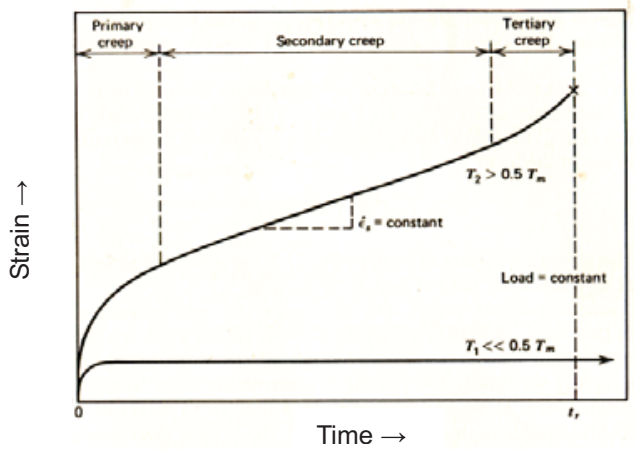

Fig. 2: Typical creep behavior includes steady state creep in the secondary creep regime.[3]

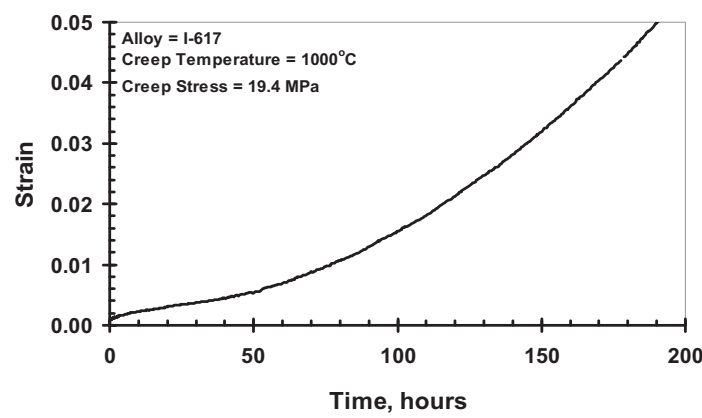

Fig. 3: A typical creep curve for Alloy 617, with little or no linear steady state creep behavior (i.e. secondary creep regime.)

\section{EXPERIMENTAL PROCEDURE}

For mechanical property testing, all specimens were machined from annealed plate; the long axis of the specimen aligned with the rolling direction.

\section{IV.A. Tensile Testing}

Elevated temperature tensile properties were measured at $50^{\circ} \mathrm{C}$ intervals for Alloy 617 and $800 \mathrm{H}$ in the temperature range of $650-1000^{\circ} \mathrm{C}$ and 500 $850^{\circ} \mathrm{C}$, respectively. Tensile specimens conformed to ASTM E21, with a $6.35 \mathrm{~mm}$ diameter reduced section and a reduced section length of $32 \mathrm{~mm}$. Room temperature tensile tests were also done (ASTM E8). Testing was performed at an initial strain rate of $1.6 \times 10^{-4} / \mathrm{s}$.

Strain rate jump tests were conducted on Alloy 617 for temperatures of $800-1000^{\circ} \mathrm{C}$ at $50^{\circ}$ intervals. Strain rate jump tests were conducted with servohydraulic test frames in strain control mode. Tests were started at a strain rate of $10^{-6} / \mathrm{s}$ and the strain rate was progressively jumped after $0.5 \%$ strain to $10^{-5}, 10^{-4}, 10^{-3}$, and $10^{-2} / \mathrm{s}$. 


\section{IV.B. Cyclic testing}

Low cycle fatigue (LCF) and creep-fatigue (CF) testing was conducted in accordance with ASTM Standard E606 on servo-hydraulic test machines in axial strain-control mode.[4] Specimen reduced sections were $7.5 \mathrm{~mm}$ diameter and $19.5 \mathrm{~mm}$ in length. Low stress grinding was used during the final machining. In all cases, radio-frequency induction heating was used to heat the specimens. The temperature gradient was measured with spotwelded thermocouples along the gage length of the specimen and was found to deviate by less than $1 \%$. Temperature control was achieved using a combination of spot-welded thermocouples on the shoulder of the specimen and a thermocouple loop at the center of the gage section.

Fully-reversed strain-controlled low cycle fatigue and creep-fatigue testing was completed at a $0.3 \%$ and a $0.6 \%$ total strain range at $950^{\circ} \mathrm{C}$. A triangular waveform (Fig. $4 \mathrm{a}$ ) and a ramp rate of $10^{-3}$ /sec were used for low cycle fatigue testing. Creepfatigue testing followed the same strain waveform except that a tensile hold ranging from $180 \mathrm{sec}$ to $1800 \mathrm{sec}(30 \mathrm{~min})$ was imposed at the maximum tensile strain (Fig. 4b).
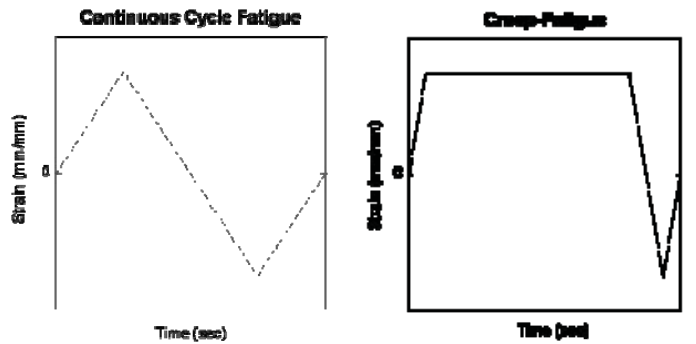

Fig. 4: Strain history of a) continuous cycle fatigue and b) creep fatigue.

The number of cycles to macro-crack initiation, $\mathrm{N}_{0}$, and the number of cycles to failure, $\mathrm{N}_{20}$, were defined as the point at which the ratio of the peak tensile stress to the peak compressive stress initially declined and the point at which the ratio was $80 \%$ of its stable value, respectively [5]. Test termination was prior to actual specimen separation.

Upon completion of a test, the test was switched into load control and the load was brought to zero before the specimen was cooled. In some cases, the failed specimen may have remained at high temperature for some time prior to cooling to room temperature. After testing, microstructural evaluation was completed to develop an understanding of the fatigue and creep-fatigue data through changes in the surface and bulk microstructure as well as in the crack failure mode.
Preliminary fatigue testing in controlled helium environments has also been performed. The controlled helium creep-fatigue system is capable of controlling gas impurity levels at the ppm level, and measuring both the inlet and outlet gas composition. Future work includes determining creep-fatigue properties in various helium environments for comparison to previous creep-fatigue results in a decarburizing helium environment.

\section{IV.C. Creep Testing}

Constant load creep tests were carried out using creep specimens, conforming to ASTM Standard E139.[6] Specimens had a $4.2 \mathrm{~mm}$ diameter and $16.6 \mathrm{~mm}$ gage length resulting in a gage length to diameter ratio of 4.0. The creep temperature was controlled to within $\pm 3^{\circ} \mathrm{C}$ of the target creep temperature. When the creep strain had approximately attained a target value, the test was terminated. Samples were then cooled from the test temperature under load. The actual creep strain was determined by measuring the increase in sample length after it had cooled to room temperature.

It should be noted that considerable heat-to-heat variation in the early stages of creep in Alloy 617 have been observed; however, little difference in the creep rate was found after approximately $5 \%$ creep strain.[7] Creep specimens were machined from an earlier heat of material, but will be duplicated using the same heat as other results reported here. Since all creep tests were run to values of creep strain that were greater than $5 \%$, the results presented here should be considered typical for Alloy 617 and the heat-to-heat variations in chemistry should have little influence on the conclusions.

\section{IV.D. Metallography}

Specimens were removed from the load frame, cut and mounted in epoxy with alumina particles for edge retention such that the long axis or stress direction was in the plane of the mount surface for a two dimensional view of the gage section. The mounts were electro-etched at 2 volts in a solution of $5 \%$ oxalic acid to create a lightly etched surface.

Optical and scanning electron microscopy with EDS analysis was then conducted. Determination of the percentage of creep void area for each sample was carried out using optical microscopy. Image analysis software was able to resolve voids on the order of $1 \mu \mathrm{m}$ in diameter. A total area of $>50 \mathrm{~mm}^{2}$ was used in image analysis to evaluate the pore fraction. The area of analysis, which was the same size for all samples, was centered over the minimum diameter of the creep specimen. 


\section{RESULTS}

\section{V.A. Tensile Behavior}

Yield and tensile strengths for the two alloys measured at various temperatures are tabulated in Table 2 and stress - strain curves are shown in Fig. 5. Alloy 617 exhibits dynamic strain aging (DSA) in the temperature regime of 600 to $850^{\circ} \mathrm{C}$ and Alloy $800 \mathrm{H}$ exhibits DSA in the temperature regime of 500 to $650^{\circ} \mathrm{C}$ at this strain rate. This behavior is manifested as serrated yielding or unstable plastic flow and is evident in Fig. 5. In the DSA regime high levels of work hardening are observed.

Above $800^{\circ} \mathrm{C}$ high levels of ductility and no appreciable work hardening are observed for both alloys. After yielding the tensile curves are relatively flat so the tensile strength is essentially equal to the yield strength.

\begin{tabular}{|c|c|c|c|}
\hline $\begin{array}{c}\text { Temperature } \\
\left({ }^{\circ} \mathrm{C}\right)\end{array}$ & $\begin{array}{c}\text { Yield } \\
\text { Strength } \\
(\mathrm{MPa})\end{array}$ & $\begin{array}{c}\text { Ultimate } \\
\text { Tensile } \\
\text { Strength } \\
(\mathrm{MPa})\end{array}$ & $\begin{array}{c}\text { Elongation } \\
(\%)\end{array}$ \\
\hline 20 & 314 & 768 & 54 \\
\hline 650 & 209 & 584 & 59 \\
\hline 700 & 249 & 553 & 49 \\
\hline 750 & 208 & 406 & 54 \\
\hline 800 & 196 & 290 & 76 \\
\hline 850 & 186 & 216 & 95 \\
\hline 900 & 163 & 166 & 83 \\
\hline 950 & 119 & 124 & 78 \\
\hline 1000 & 89.9 & 92 & 80 \\
\hline
\end{tabular}

a)

\begin{tabular}{|c|c|c|c|}
\hline $\begin{array}{c}\text { Temperature } \\
\left({ }^{\circ} \mathrm{C}\right)\end{array}$ & $\begin{array}{c}\text { Yield } \\
\text { Strength } \\
(\mathrm{MPa})\end{array}$ & $\begin{array}{c}\text { Ultimate } \\
\text { Tensile } \\
\text { Strength } \\
(\mathrm{MPa})\end{array}$ & $\begin{array}{c}\text { Elongation } \\
(\%)\end{array}$ \\
\hline 20 & 234 & 553 & 54 \\
\hline 500 & 143 & 484 & 41 \\
\hline 550 & 136 & 467 & 43 \\
\hline 600 & 135 & 445 & 39 \\
\hline 650 & 146 & 407 & 26 \\
\hline 700 & 134 & 321 & 19 \\
\hline 750 & 140 & 234 & 37 \\
\hline 800 & 140 & 150 & 65 \\
\hline 850 & 100 & 109 & 58 \\
\hline
\end{tabular}

b)

Table 2: Tensile test results for a) Alloy 617 and b) Alloy $800 \mathrm{H}$.
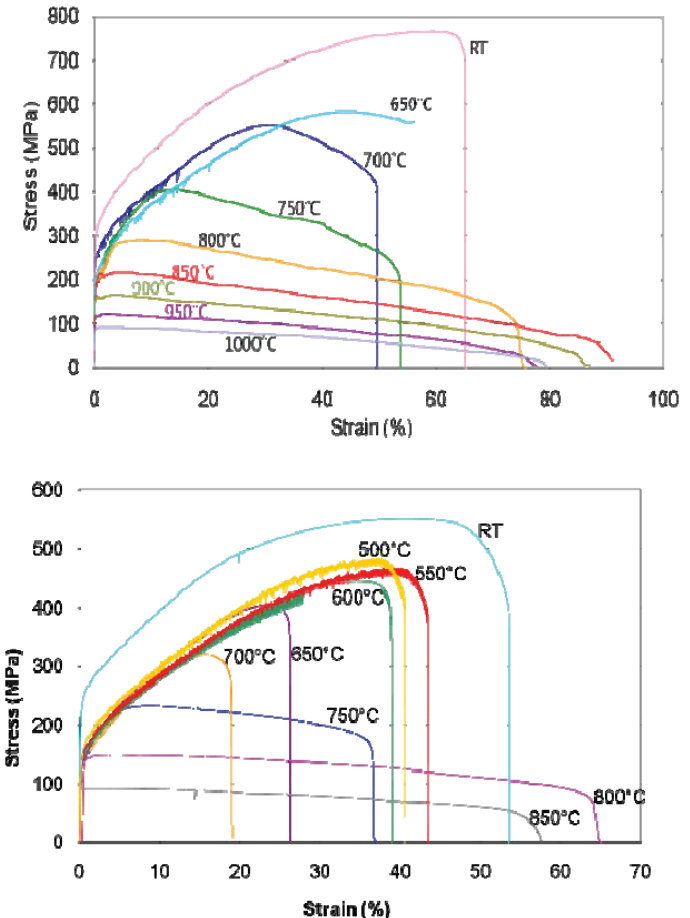

Fig. 5: Tensile stress-strain curves for a) Alloy 617 and b) Alloy $800 \mathrm{H}$.

\section{V.B. Strain Rate Sensitivity}

Alloy 617 is highly strain rate sensitive at the highest temperatures. Fig. 6 shows results of strain rate jump tests run at temperatures from 800$1000^{\circ} \mathrm{C}$. Increasing the strain rate gives rise to higher flow stresses. For example at $900^{\circ} \mathrm{C}$ the stress increases from $50 \mathrm{MPa}$ at $10^{-6} / \mathrm{sec}$ to $250 \mathrm{MPa}$ at $10^{-}$ $2 /$ sec. Detailed modeling is required for a unified constitutive model.

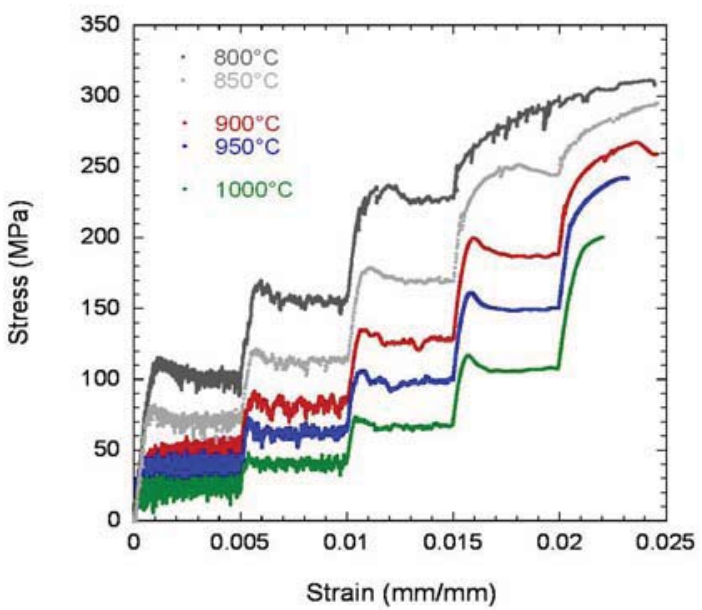

Fig. 6: Strain rate jump tests of Alloy 617. 
It is also interesting to note that work hardening is not observed except for at the highest strain rate of $10^{-2} / \mathrm{sec}$ (also $10^{-3} / \mathrm{sec}$ for $800^{\circ} \mathrm{C}$ ). The flow stresses observed at the $10^{-4} / \mathrm{sec}$ strain rate correlate relatively well with the yield strengths measured during high temperature tensile testing. DSA is observed at lower temperatures and faster strain rates. DSA is not observed at temperatures of $900^{\circ} \mathrm{C}$ and above.

Flow stress and strain rate are related at a constant temperature and strain by the following equation:

$\boldsymbol{\nabla} \mathbf{v}(\mathbf{f})^{\mathrm{m}}$

where $\mathrm{C}$ is a constant, $\sigma$ is the flow stress, $\vec{c}$ is the strain rate, and $\mathrm{m}$ is the strain rate sensitivity. Strain rate sensitivity values were calculated[8] and are tabulated in Table 3 for temperatures from $800^{\circ} \mathrm{C}$ to $1000^{\circ} \mathrm{C}$. Values were not calculated for jumps to the highest strain rate because the rounded shape of the stress-strain curve (Fig. 6) made determining the stress after the jump problematic. The strain rate sensitivity is about 0.17 for all temperatures and strain rates measured.

\begin{tabular}{|c|c|c|c|c|c|}
\hline \multirow{2}{*}{$\begin{array}{c}\text { strain rate } \\
\text { (/sec) }\end{array}$} & \multicolumn{5}{|c|}{ Temperature $\left({ }^{\circ} \mathrm{C}\right)$} \\
\cline { 2 - 6 } & 800 & 850 & 900 & 950 & 1000 \\
\hline $10^{-6}$ to $10^{-5}$ & 0.17 & 0.18 & 0.17 & 0.15 & 0.16 \\
\hline $10^{-5}$ to $10^{-4}$ & 0.16 & 0.16 & 0.16 & 0.18 & 0.18 \\
\hline $10^{-4}$ to $10^{-3}$ & - & 0.16 & 0.16 & 0.18 & 0.19 \\
\hline regression fit & 0.16 & 0.17 & 0.17 & 0.17 & 0.18 \\
\hline
\end{tabular}

Table 3: Strain rate sensitivity, $\mathrm{m}$, values.

\section{V.C. Low Cycle Fatigue Behavior}

Continuous low cycle fatigue (LCF) testing was completed in air at $950^{\circ} \mathrm{C}$ to provide a baseline for the creep-fatigue behavior. Two strain ranges were investigated, $0.3 \%$ and $0.6 \%$ total strain. The test conditions, number of cycles to failure, inelastic strain at a midlife cycle, and the total test time are listed in Table 4.

The peak tensile and compressive stresses observed in the LCF tests at $0.3 \%$ and $0.6 \%$ total strain were relatively symmetrical, i.e. the peak tensile and compressive stresses were of the same magnitude, as shown in Fig. 8(a) and Fig. 9(a), respectively. The peak tensile stresses as a function of cycle reached a stable value within less than 10 cycles at $0.3 \%$ total strain and within 5 cycles at $0.6 \%$ total strain.

Furthermore, the steady state stress remained constant until macrocrack initiation or just prior to failure. For the $0.6 \%$ total strain tests, the peak stresses of the initial cycles were greater in magnitude than the steady state stress. Also, note that the steady state peak stress in the $0.6 \%$ total strain test was similar in magnitude to the $0.3 \%$ total strain test. This is consistent with the shape of the cyclic stress-strain hysteresis plots shown in Fig. 8(b) and Fig. 9(b) for the $0.3 \%$ and $0.6 \%$ total strain conditions, respectively. The hysteresis plots, shown in Fig. 8(c) and Fig. 9(c), were relatively unchanging for cycles 9, 99, and 999 and thus the inelastic strain also did not change significantly as a function of cycle.

\begin{tabular}{|l|l|l|l|l|l|}
\hline $\begin{array}{l}\text { Total } \\
\text { strain } \\
\text { range } \\
(\%)\end{array}$ & $\begin{array}{l}\text { Hold } \\
\text { time } \\
(\mathrm{min})\end{array}$ & $\begin{array}{l}\text { Cycles to } \\
\text { initiation }\end{array}$ & $\begin{array}{l}\text { Cycles } \\
\text { to } \\
\text { failure }\end{array}$ & $\begin{array}{l}\text { Time } \\
\text { to } \\
\text { failure } \\
\text { (h) }\end{array}$ & $\begin{array}{l}\text { Inelastic } \\
\text { strain @ } \\
\text { midlife } \\
(\%)\end{array}$ \\
\hline 0.3 & 0 & 8639 & 9641 & 16 & 0.102 \\
\hline 0.3 & 0 & 5033 & 5867 & 9 & 0.105 \\
\hline 0.3 & 0 & 8139 & 9000 & 15 & 0.084 \\
\hline 0.3 & 3 & 2600 & 3989 & 206 & 0.202 \\
\hline 0.3 & 3 & 1944 & 2485 & 128 & 0.212 \\
\hline 0.3 & 10 & 3583 & 4096 & 689 & 0.199 \\
\hline 0.3 & 10 & 3589 & 4430 & 745 & 0.200 \\
\hline 0.6 & 0 & 783 & 1722 & 6 & 0.436 \\
\hline 0.6 & 0 & 762 & 1390 & 5 & 0.441 \\
\hline 0.6 & 0 & 826 & 1480 & 5 & 0.441 \\
\hline 0.6 & 3 & 450 & 950 & 51 & 0.488 \\
\hline 0.6 & 3 & 297 & 922 & 49 & 0.503 \\
\hline 0.6 & 10 & 402 & 686 & 117 & 0.510 \\
\hline 0.6 & 10 & 416 & 634 & 108 & 0.506 \\
\hline 0.6 & 30 & 367 & 661 & 333 & 0.524 \\
\hline
\end{tabular}

Table 4: Fatigue and creep-fatigue tests completed at $950^{\circ} \mathrm{C}$ and a strain rate of $10^{-3} / \mathrm{sec}$. [4]

The continuous cycle fatigue life observed for Alloy 617 is similar to that reported for Alloy 617 by Meurer et al. in air.[1] and Rao et al. at the $0.6 \%$ total strain range in a simulated nuclear reactor helium environment.[9] One continuous cycle fatigue test was completed in a helium environment with $53 \mathrm{ppm} \mathrm{CO}$ and $352 \mathrm{ppm} \mathrm{H}_{2}$ at $950^{\circ} \mathrm{C}$ and $0.3 \%$ total strain. The cycles to failure and peak stress vs. cycle profile are similar to the tests performed in air, as shown in Fig. 7.

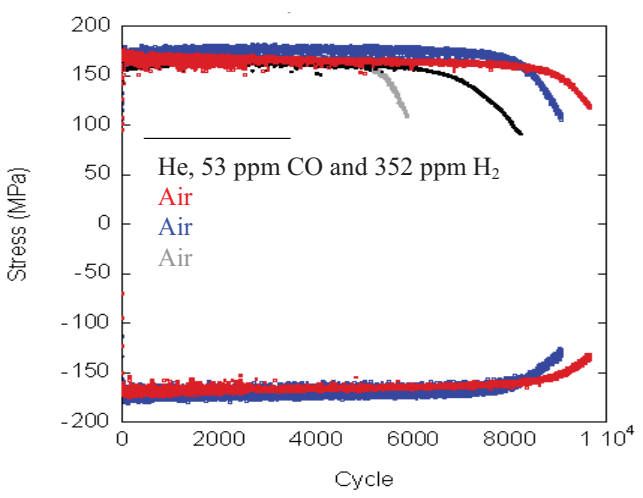

Fig. 7: Peak tensile and compressive stresses as a function of cycle for continuous cycle fatigue testing at $950^{\circ} \mathrm{C}, 0.3 \%$ total strain conducted in air and helium. 


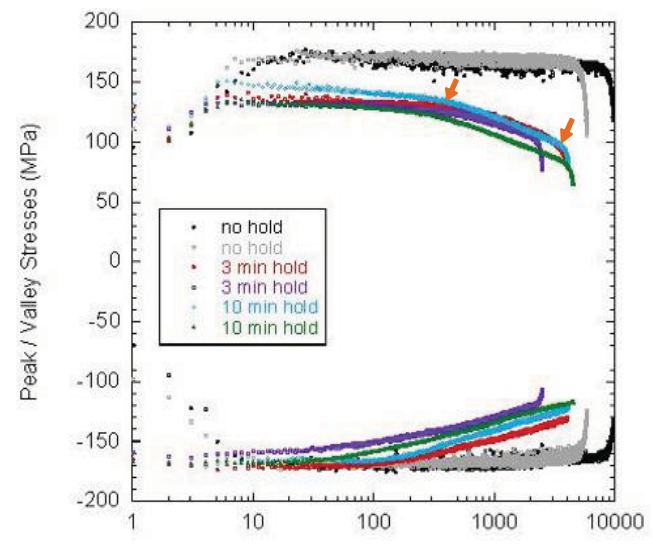

a.

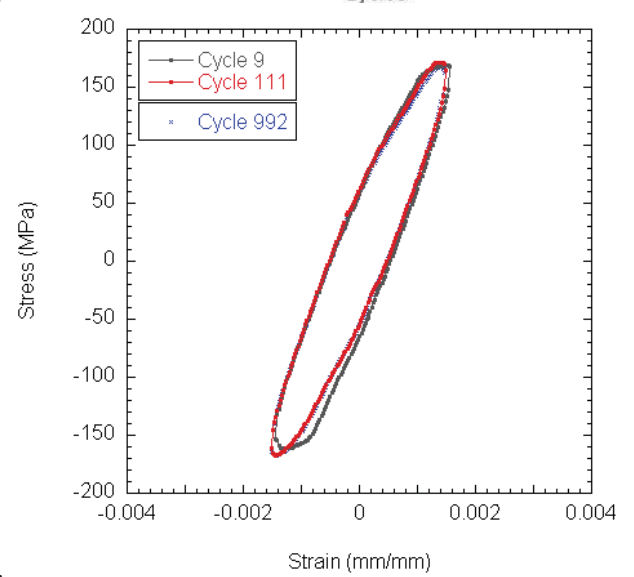

b.

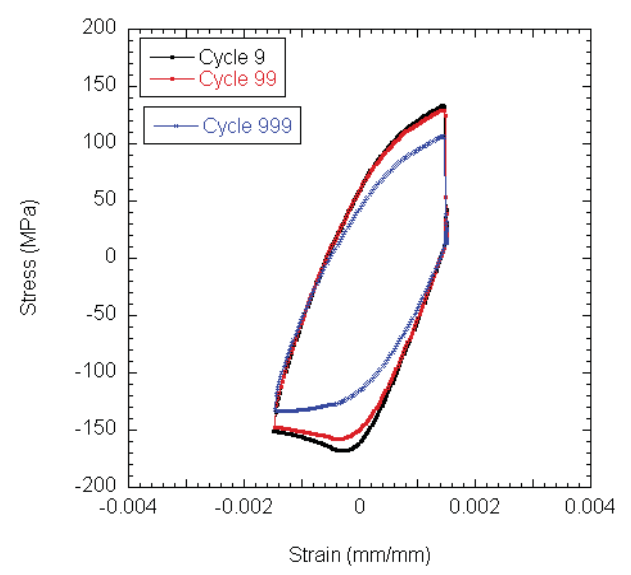

c.

Fig. 8: Peak tensile and compressive stress plotted as a function of cycle for creep-fatigue tests at $950^{\circ} \mathrm{C}$ and a $0.3 \%$ total strain range (a). Arrows indicate two characteristic transition points, following which peak stresses decrease more rapidly. Stress-strain hysteresis plots for the no hold (b) and $10 \mathrm{~min}$ hold (c) creep-fatigue test shown for selected cycles.[4]
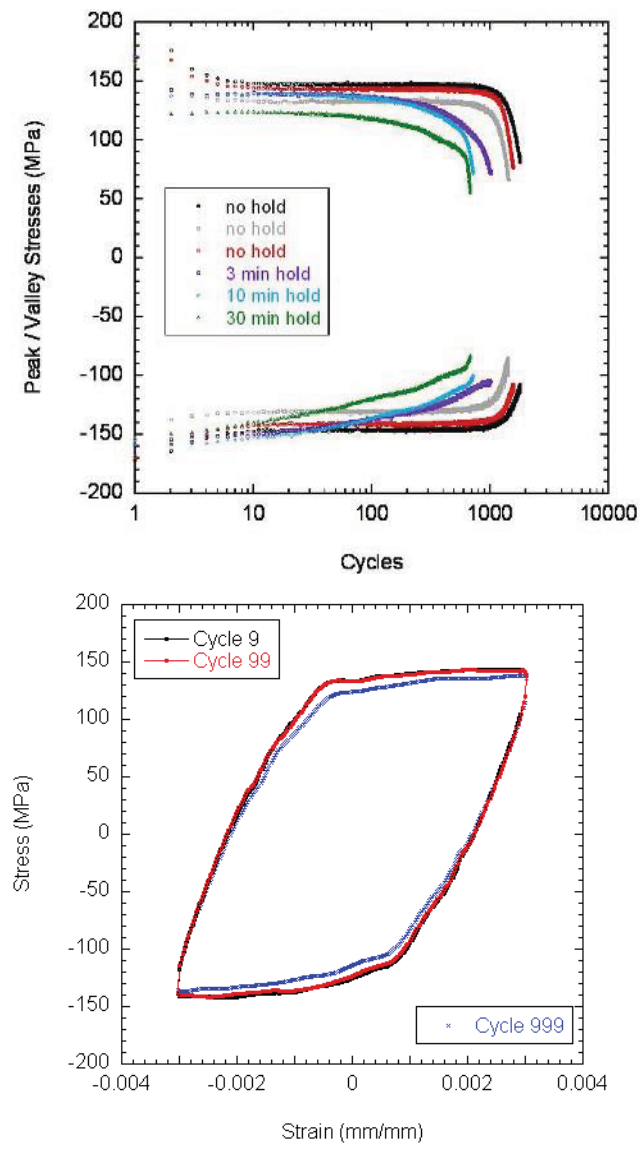

b.

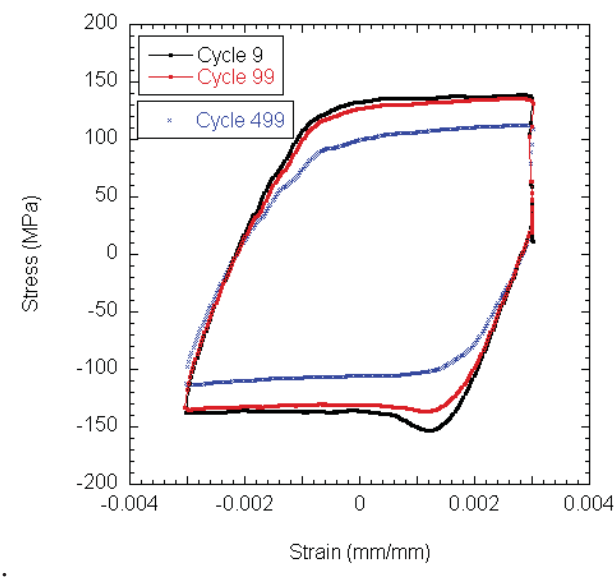

c.

Fig. 9: Peak tensile and compressive stress plotted as a function of cycle for creep-fatigue tests at $950^{\circ} \mathrm{C}$ and a $0.6 \%$ total strain range (a). Stress-strain hysteresis plots for the no hold (b) and 10 min hold (c) creep-fatigue test shown for selected cycles.[4] 


\section{V.D. Creep-Fatigue Behavior}

Creep-fatigue testing was also conducted at $950^{\circ} \mathrm{C}$ in air with tensile hold times of up to 1800 sec. A list of the creep-fatigue conditions and the baseline fatigue data are shown in Table 4; total test times were as long as 1 month. Intergranular crack initiation and propagation was observed in all of the low cycle fatigue and creep-fatigue specimens cycled at $950^{\circ} \mathrm{C}$, regardless of strain range. Chromia was present on both crack and specimen surfaces.[4] Alumina was present at the crack tip and along intersecting grain boundaries.

The introduction of hold times at peak tensile strain in continuous cycle fatigue reduces the fatigue life of Alloy 617. The number of cycles to failure decreased with increasing tensile hold times for both strain ranges, as shown in Fig. 10. Lines are shown on the plot but are not meant to accurately capture the trend with hold time.

The peak tensile and compressive stresses are shown as a function of cycle for the creep-fatigue tests in Fig. 8(a) and Fig. 9(a). The creep-fatigue peak stresses versus cycle profiles were similar regardless of the duration of the tensile hold. The peak stresses did not achieve a steady state value. Instead the peak stress slowly decreased with increasing cycles and generally had two transition points following which a more rapid decrease was observed. The creep-fatigue peak stresses versus cycle profiles were also relatively symmetric, although the magnitudes of the stresses in compression were slightly greater than in tension. The hysteresis plots shown in Fig. 8(c) and Fig. 9(c) illustrate the decreasing magnitude of the peak stresses at later cycles. The plots shown for cycles 499 and 999 illustrate this lower peak stress magnitude, although the width of the loops at zero strain, the inelastic strain, did not vary greatly.

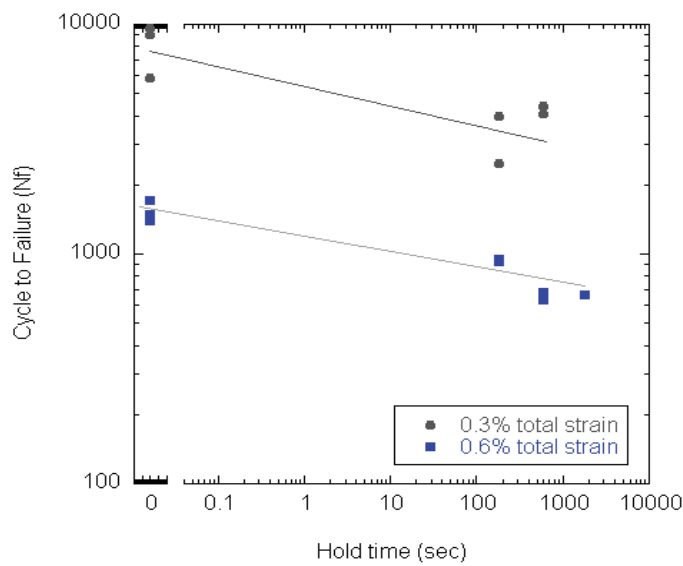

Fig. 10: Cycles to failure as a function of hold time for creep-fatigue testing at $950^{\circ} \mathrm{C}$.[4]
In the case of the $0.3 \%$ total strain range, the addition of a 3 minute hold time reduced the number of cycles to failure by a factor of 2 . An increase in hold time to 10 minutes did not further reduce the cycle life. At the $0.6 \%$ total strain range, the addition of a hold time resulted in reductions in the cycles to failure, although the 30 minute hold time test may not further reduce the creep-fatigue life. Due to the variability observed in fatigue and creepfatigue more data is necessary to illicit the influence of an increasing hold time on cycle life.

Stress relaxation curves are shown for the $0.6 \%$ strain range for creep-fatigue tests at $950^{\circ} \mathrm{C}$ with a $180 \mathrm{sec}$ and $600 \mathrm{sec}$ hold time in Fig. 11. The stress relaxation during the hold period at constant strain occurred at the same rate for the $180 \mathrm{sec}$ and the 600 sec hold. Initially the stress decreased rapidly until approximately $60 \mathrm{sec}$ into the hold. The creep rate may be calculated from the slope of these curves and the elastic modulus. Regardless of the starting strain/stress the stresses relaxed in a similar manner.

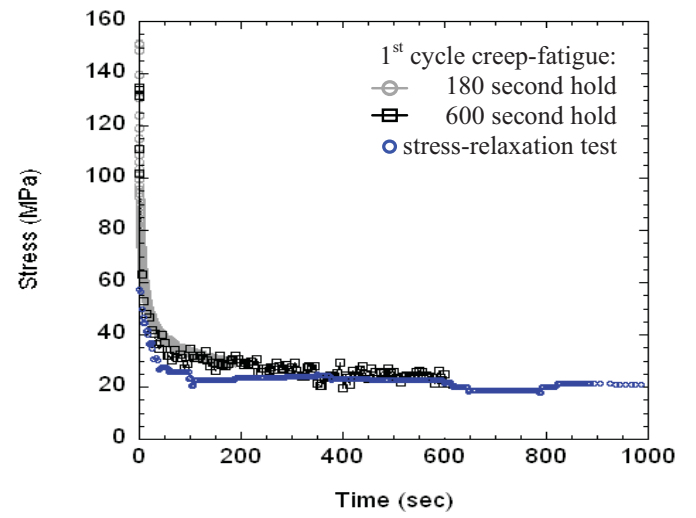

Fig. 11: Stress relaxation curves at $950{ }^{\circ} \mathrm{C}$ comparing first cycle of creep-fatigue tests at $0.6 \%$ total strain range to stress-relaxation test.

\section{V.E. Creep}

Table 5 shows the conditions and creep strain at test termination for each sample. The transition to tertiary creep typically occurred prior to reaching a creep strain of $0.5 \%$, typically less than 50 hours, and the samples spent most of their creep lives, which lasted from 97 to 650 hours, in the tertiary regime (Fig. 3). Creep tests were terminated between creep strain values of 5 and $41 \%$.

An increase in porosity with strain is evidence of creep damage. Fig. 12 shows the amount of porosity as a function of the creep strain for the three different load-temperature conditions; however no clear differences in the amount of porosity as a function of strain are exhibited for the different loads and temperatures. Fig. 13 shows the porosity distribution in Alloy 617 after creep testing at $1000^{\circ} \mathrm{C}$ 


\begin{tabular}{|l|l|l|l|}
\hline $\begin{array}{l}\text { Creep } \\
\text { Temperature } \\
\left({ }^{\circ} \mathrm{C}\right)\end{array}$ & $\begin{array}{l}\text { Creep } \\
\text { Stress } \\
(\mathrm{MPa})\end{array}$ & $\begin{array}{l}\text { Creep } \\
\text { Strain } \\
(\%)\end{array}$ & $\begin{array}{l}\text { Test } \\
\text { Duration } \\
(\mathrm{h})\end{array}$ \\
\hline 1000 & 22.9 & 7.1 & 97.0 \\
\hline 1000 & 23.0 & 24.2 & 150.0 \\
\hline 1000 & 22.6 & 41.4 & 134.7 \\
\hline 1000 & 25.9 & 23.1 & 158.5 \\
\hline 1000 & 23.8 & 17.0 & 115.4 \\
\hline 1000 & 19.4 & 23.6 & 241.3 \\
\hline 1000 & 19.4 & 20.4 & 312.2 \\
\hline 1000 & 19.4 & 17.7 & 333.9 \\
\hline 1000 & 19.5 & 4.9 & 111.3 \\
\hline 900 & 39.1 & 16.5 & 650.7 \\
\hline 900 & 39.1 & 12.5 & 427.6 \\
\hline
\end{tabular}

Table 5: Creep Conditions for Alloy 617.[6]

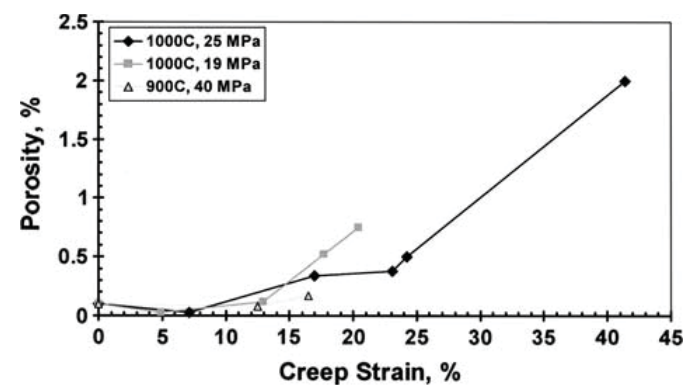

Fig. 12: Porosity as a function of creep strain for Alloy 617.[6]

\section{DISCUSSION}

\section{VI.A. Fatigue and Creep Fatigue}

The high degree of strain-rate sensitivity for monotonic testing exhibited by Alloy 617 suggests that the creep-fatigue properties are also dependent on strain rate. The stress strain behavior and thus, the cyclical peak stresses and hysteresis loops are a function of strain rate. Previous work has indicated that this is in fact the case; decreasing the strain rate results in lower fatigue lifetimes.[9]

The continuous cycle fatigue and creep-fatigue hysteresis plots observed at $950^{\circ} \mathrm{C}$ are consistent with the tensile curves and strain rate change results. At the high strain range, the alloy becomes purely plastic and little hardening is observed. Also consistent is the fact that the peak stresses observed at the higher strain range are not significantly different than those observed during the lower strain range tests, as shown in Fig. 8(a) and Fig. 9(a).

Also important for modeling of creep-fatigue is an understanding of the failure mechanism. Typically three types of failure are defined: fatiguedominated, creep-dominated, and creep-fatigue interaction, when the creep and fatigue damage processes interact and accelerate the deformation process. Fatigue dominated failures are typically observed at lower to intermediate temperatures and transgranular crack initiation and propagation is observed. In contrast, creep dominated failures occur at high temperatures and intergranular crack initiation and propagation with extensive creep cavitation occurs. Creep-fatigue interaction is exemplified as mixed-mode crack propagation and the presence of creep cavitation on the grain boundaries in the bulk material. In the case of the fatigue and creep-fatigue testing reported here, the failures appear to be creep dominated as only intergranular cracking was observed. However, creep cavitation was not observed on the grain boundaries of any of the specimens tested in air. It should be noted that care during etching is required to differentiate between creep cavities and etching artifacts. [10] Over-etching of Alloy 617 produces a microstructure that appears to have grain boundary cavities but a lighter etch reveals the presence of precipitates.

Grain boundary cavitation has been observed after creep-fatigue testing under similar conditions but in a decarburizing helium environment. [9] Creep cavitation and wedge cracks were observed predominately near the surface and occurred within the decarburized region. The fatigue specimen tested in a helium environment, $\left(\sim 10^{-4} / \mathrm{sec}\right)$, exhibited a crack propagation mode that switched to intergranular [6]. The addition of a $60 \mathrm{sec}$ tensile hold also resulted in the cracking initiating transgranularly and propagating by a mixed mode [9]. The different deformation mechanisms may result from the variations in microstructure resulting
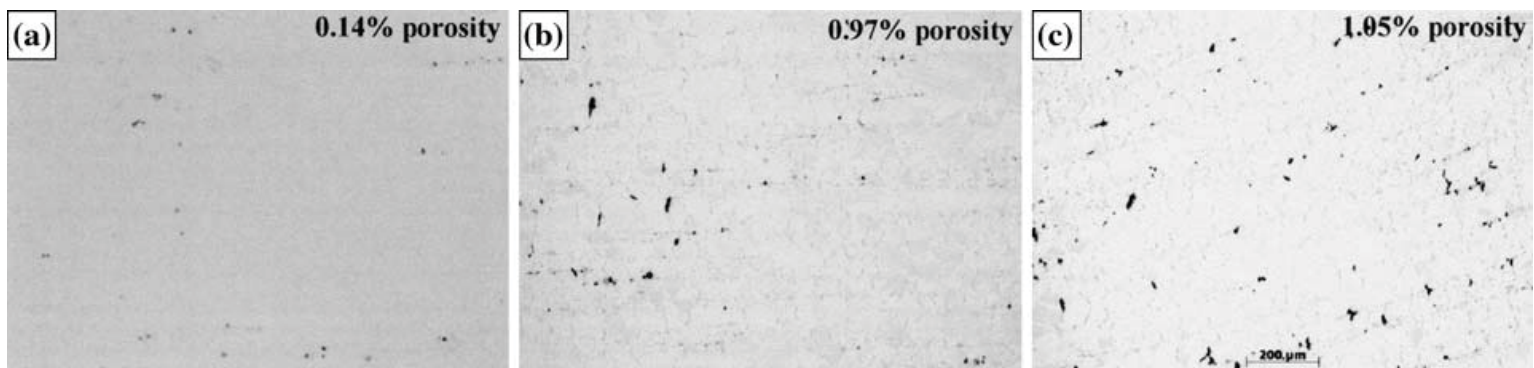

Fig. 13: Micrographs showing the porosity resulting from creep of Alloy 617 at $1000^{\circ} \mathrm{C}$ and (a) $5 \%$, (b) $15 \%$, and (c) $25 \%$ creep strain.[6] 
from cycling in different environments. This hypothesis will be further investigated by conducting creep-fatigue testing in various helium environments.

Grain boundary cavitation is not expected in this material until large creep strains (as discussed in the following section), which is consistent with the absence of grain boundary cavitation during creepfatigue deformation.

\section{VI.B. Creep}

During the constant load uniaxial creep testing at $900^{\circ} \mathrm{C}$ and $1000^{\circ} \mathrm{C}$, creep cavitation did not occur in Alloy 617 until greater than $\sim 10 \%$ creep strain [6]. Very limited cavity formation is observed in this alloy and a critical amount of creep deformation is required before creep cavities nucleate.

During constant load tertiary creep, the strain rate increases with increasing strain. The maximum creep rate, calculated just prior to test termination, varied by roughly an order of magnitude $\left(2 \times 10^{-7} / \mathrm{s}\right.$ to $2 \times 10^{-6} / \mathrm{s}$ ) for the creep conditions in this study. Therefore, the dominant creep mechanism during tertiary creep was, quite likely, the same for all samples and can be expected to produce little difference in plots of porosity vs. creep strain. The interesting result, from an engineering point of view, is that a substantial amount of tertiary creep $(\sim 10 \%)$ can occur before porosity becomes significant for this alloy.

\section{CONCLUSION}

Continuous cycle fatigue and creep-fatigue testing of Alloy 617 was conducted at $950^{\circ} \mathrm{C}$ and $0.3 \%$ and $0.6 \%$ total strain in air to simulate damage modes expected in a VHTR application. Continuous cycle and creep-fatigue specimens exhibited intergranular cracking, but did not show evidence of grain boundary cavitation. Despite the absence of grain boundary cavitation to accelerate crack propagation, the addition of a hold time at peak tensile strain was detrimental to cycle life. From the creep-fatigue data, it is not possible to determine whether the creep-fatigue life saturates with increasing hold time. Long hold time creep-fatigue tests are planned as are creep-fatigue tests in a simulated helium environment to further address needs identified by the Alloy 617 draft Code Case.

Evaluation of the relationship between the percentage of void area in the microstructure of Alloy 617 creep specimens and the amount of creep strain shows increasing porosity with increasing creep strain; however, creep stress and temperature did not have a strong influence on this relationship for the conditions studied. From an engineering perspective, the most interesting result is that significant tertiary creep occurs $(\sim 10 \%)$ before significant void fractions are observed in the crept microstructure.

\section{REFERENCES}

[1] Meurer H. P., et al., Investigations on the Fatigue Behavior of High-Temperature Alloys for HighTemperature Gas-Cooled Reactor Components, Nuclear Technology, 66, 2, p. 315, 1984.

[2] Swindeman R. W., et al., Task 1. Report on the Review of Databases, Data Analysis Procedures and Verification of Minimum and Ultimate Strengths for Alloy $800 \mathrm{H}$ in ASME Section III, Subsection NH; March, 2007.

[3] Dieter G., Mechanical Metallurgy, 2nd edition, New York, McGraw-Hill Book Company, 1976.

[4] Carroll L., et al., The Role of Environment on High Temperature Creep-Fatigue Behavior of Alloy 617 Proceedings of the ASME 2010 Pressure Vessel and Piping Division Conference, Bellevue, Washington, July 18-22, 2010.

[5] Totemeier T. and Tian H., Creep-FatigueEnvironment Interactions in Inconel 617, Materials Science and Engineering A, 468-470, p. 81, 2007.

[6] Lillo T., et al., Influence of Grain Boundary Character on Creep Void Formation in Alloy 617, Metallurgical and Materials Transactions A, 40A, 12, p. 2803, 2009.

[7] Swindeman R. W. and Swindeman M. J., A Comparison of Creep Models for Nickel Base Alloys for Advanced Energy Systems, International Journal of Pressure Vessels and Piping, 85, 1-2, p. 72, 2008.

[8] Mulford R. A. and Kocks U. F., New Observations on the Mechanisms of Dynamic Strain Aging and of Jerky Flow, Acta Metallurgica, 27, p. 1125, 1979.

[9] Rao K. B. S., et al., Creep-Fatigue Interaction of Inconel 617 at $950^{\circ} \mathrm{C}$ in Simulated Nuclear Reactor Helium, Metallurgical Transactions A, 19A, p. 359, 1988.

[10]Hales R., A Quantitative Metallographic Assessment of Structural Degradation of Type 316 Stainless Steel During Creep-Fatigue, Fatigue of Engineering Materials and Structures, 3, 4, p. 339, 1980.

\section{ACKNOWLEDGMENTS}

The authors would like to acknowledge Tammy Trowbridge and Todd Morris for the metallurgical work. This work was supported through the U.S. Department of Energy, Office of Nuclear Energy. 